\title{
MRS Publishes Proceedings of Workshop on Tungsten and Other Refractory Metals for VLSI Applications
}

The Materials Research Society has published the proceedings of the second annual Workshop on Tungsten and Other Refractory Metals for VLSI Applications in a special hardbound volume. The volume contains the papers presented at the second Workshop, held October 9-11, 1985 at Sandia National Laboratories, Albuquerque, NM, as well as key papers presented at the first Workshop held at Sandia in 1984.

Because tungsten is self-aligning when applied by low-pressure CVD (LPCVD), it simplifies the problem of devising diffusion barriers to protect electrical contacts between $\mathrm{Si}$ diffusions and $\mathrm{Al}$ interconnects. Also, its electrical conductivity is several times higher than that of tungsten silicide and other similar high-melting point metal compounds being considered for use in advanced microcircuits. Because it can be deposited in a self-aligning manner, areaselective LPCVD tungsten is also being adapted for applications such as source flash drain covers, via fills and low resistance shunts on polysilicon lines.

The highly successful Workshop series, chaired by Robert S. Blewer of Sandia National Laboratories, attracted more than 100 scientists and engineers from 51 U.S. and nine foreign companies. The 34 papers published in the proceedings cover selective deposition of tungsten-past and present, recent developments in LPCVD tungsten, fundamental studies of LPCVD tungsten films, properties of CVD tungsten films deposited at atmospheric and reduced pressures, adhesion of tungsten films to dielectrics, the influence of dopants and silicon dioxide on the reduction of $W_{6}$ by silicon and hydrogen, practical aspects of LPCVD tungsten, properties of blanket tungsten films deposited by sputtering and LPCVD, devices and techniques, electrical properties of tungsten films on silicon, and properties of refractory metal films on GaAs. The keynote paper, presented by Pallab Chatterjee, director of VLSI Design at Texas Instruments, is entitled "Interconnects and VLSI-A Device Designer's Perspective."

Papers from the 1984 Workshop included in the volume total 25 , and cover LPCVD tungsten techniques; source gas purity, analysis, and flow control; properties and characteristics of tungsten films; tungsten/ silicon interaction; modeling; device applications; and the future of refractory metals in VLSI applications. The keynote paper, by A. N. Saxena, Gould/AMI, is entitled "VLSI Multilevel Metallizations: The Role of Tungsten."

Sandia National Laboratories organized the 1985 Workshop jointly with the University of California-Berkeley's University Engineering Extension to gauge interest in this technology, to identify laboratories in this field, and to provide an opportunity for those beginning research in this area to exchange results. The 1985 Workshop was twice the length of the 1984 Workshop to accommodate the growing amount of new information and interest in tungsten for VLSI applications.

The volume marks the first time that MRS has published the proceedings of a conference which was not sponsored by MRS. The 59 contributed and reviewed papers contained in this volume represent more than $75 \%$ of the research published on LPCVD tungsten in the last five years. The book thus represents a valuable contribution to the literature on materials research for integrated circuits, and serves as an important reference book for members of the Society and others involved in materials research in the semiconductor industry.

The book, Tungsten and Other Refractory Mitals for VLSI Applications, can be ordered from MRS at the following prices:

Until April 30, 1986:

MRS members- $\$ 29$

U.S. nonmembers $-\$ 34$

Foreign nonmembers $-\$ 40$

After April 30, 1986:

MRS members-\$34

U.S. nonmembers- $\$ 39$

Foreign nonmembers $-\$ 45$

Order from Publications Department, Materials Research Society, 9800 McKnight Road, Suite 327, Pittsburgh, PA 15237; telephone (412) 367-3012

MIRS

\section{Von Hippel Award Nominations Sought}

\author{
The Society's Most Prestigious Honor
}

The Awards Conmittee of MRS, chaired by Past President Elton Kaufmann, has announced that nominations are being accepted for the Society's highest award, the Von Hippel Award of the Materials Research Society. The Award is an international hallmark of excellence in the field of materials research, numbering nine prominent materials scientists as past recipients.

The Award is named for the Emeritus Professor of the Massachusetts Institute of Technology, Arthur von Hippel, whose laboratory pioneered the collaborative, interdisciplinary research that subsequently has taken the identity of "materials science." It recognizes those qualities most prized by materials scientists-brilliance and originality of intellect, combined with vision that transcends conventional scientific disciplines. The Award is presented annually by the Society at its Fall Meeting.

Past recipients of the Award are:

Prof. Arthur von Hippel

Dr. William O. Baker

Prof. David Turnbull

Prof. W. Conyers Herring

Prof. James $W$. Mayer

Prof. Clarence $M$. Zener

Prof. Sir Peter B. Hirsch

Dr. Walter L. Brown

Dr. John W. Cahn

The recipient is selected by majority vote of the MRS Council from a slate of candidates that is prepared by the Awards Committee. Nominations should be made to the MRS Awards Committee. Names put into nomination are, in accordance with MRS By-Laws, considered active for three years. Nominations must be made using the Von Hippel Award Nomination Form and should be accompanied by supporting documentation. Initial screening of candidates will be based upon the information contained on the summary form.

Nominations should be sent to: Elton $\mathrm{N}$. Kaufmann, Lawrence Livermore National Laboratory, P.O. Box 808, L-370, Livermore, CA 94550

NOMINATION DEADLINE: July 1, 1986

Additional copies of the Von Hippel Award Nomination Form may be obtained from MRS Headquarters.

MRS 